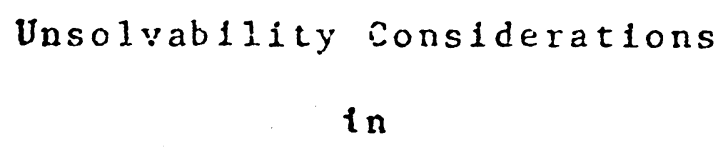

Computationa: Complexity

by

Forbes Lewis

.

rechnical Report

$70 \cdot 60$

Apri1 $1 \subseteq 70$

Denartment of Computer science

Cornell University

Ithaca New York 14850 

JNSOIVABILITY CONSIDERATIONS

IN

COMPUTATIONAL COMELEXITY

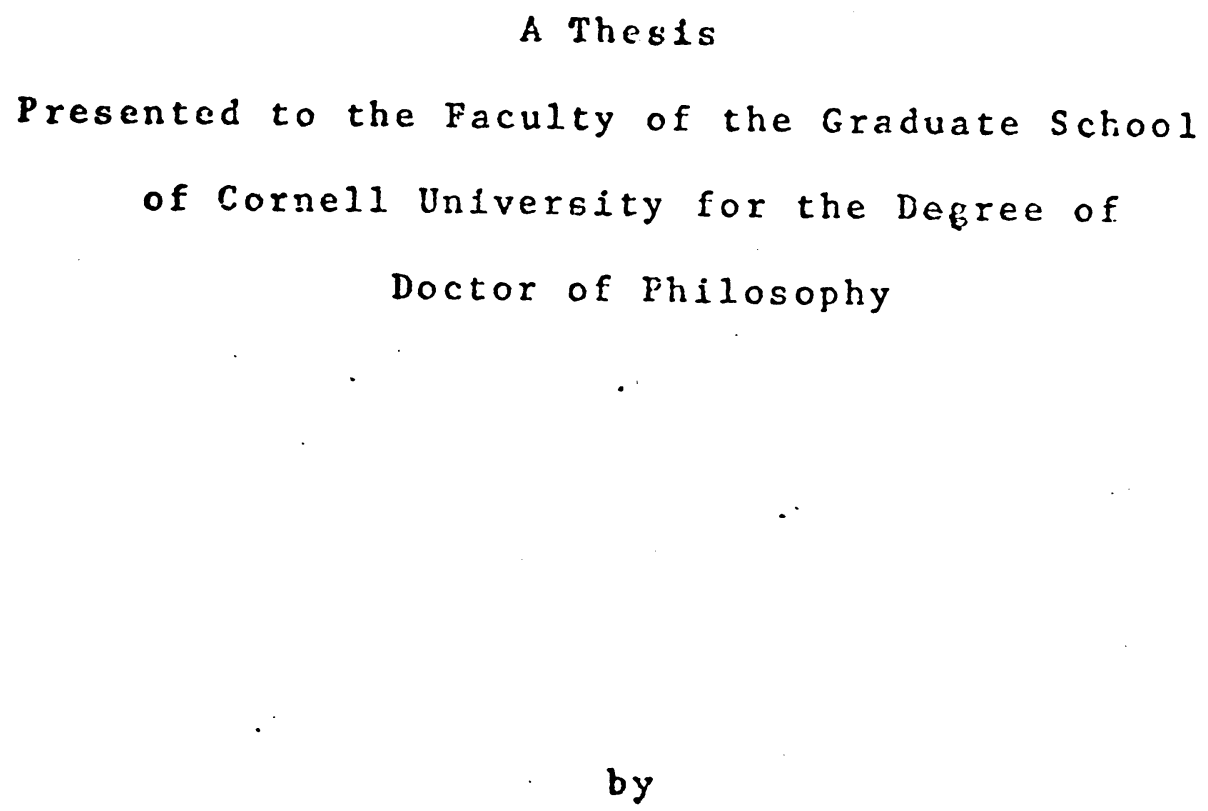

Forbes Downer Lew1s

June 1970 

In this paper severai undecldability aspects of complexity classes and sets assoclated with then will be examlned. These sets will be classlfled by thelr degree of unsolvablitty and restrlcticns will be placed on neasures sc that thege deprees are 1dentical. Th1s glves rise to a new crlterion for the "saturalness" of zeasurcs and to suggestions for strengthening the mezsures of complexity. 


\section{Forbes Lew 1s was born in Hew Haven.}

Connectscut on Apr11 25,1942. He served with the 101st Alrborne Division of the Urited states Army between 1960 and 1963 . In 1957 he graduated from Cornell Undversity where he nagored in Computer sclence and recelved 3.S. degree. He began graduate studles in the separtient of Computer Science at Cornell in Septenber, 1967. 


\section{Acknowledgencota}

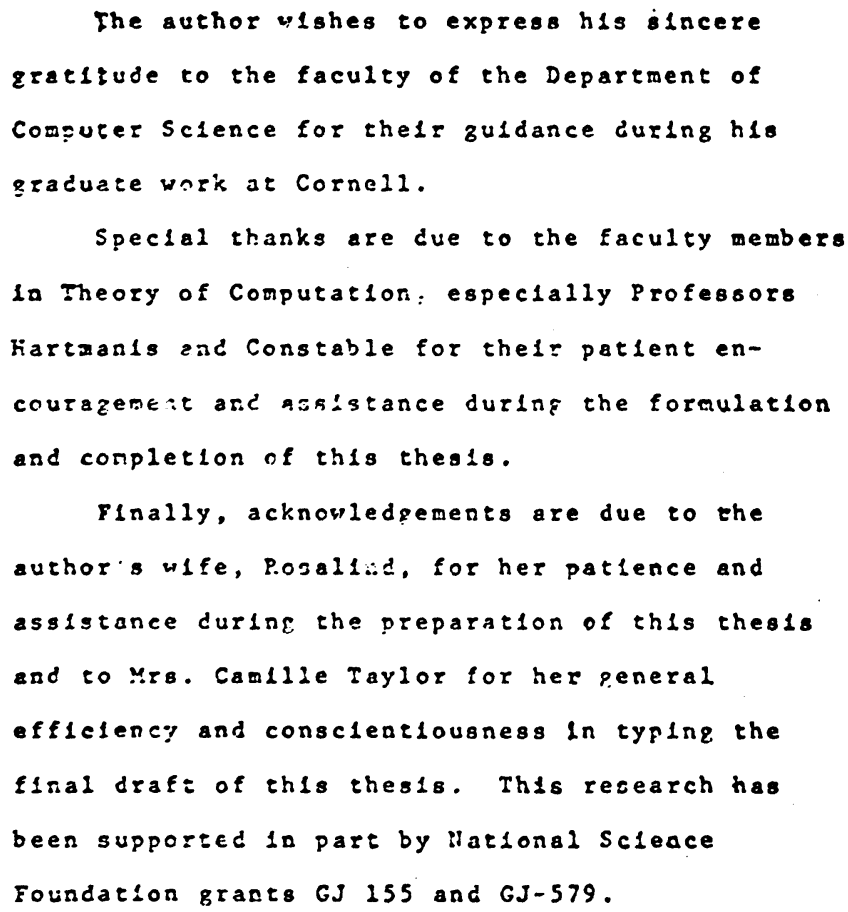


Table of Contents

page

Chapter 1. Introduction I

1.1 General Background

1.2 Outine of Thes18 5

Chapter 2. State of the Art (W1th Two Axtoms) 9

2.1 Complexlty Classes S

2.2 Unsolvability Preliminarles is

2.3 A Criterion for Measures 20

2.4 Index Sets of Complexity Classes 23

2.5 Other sets in Complexlty Theory 27

2.6 Conformley Relationships 30

Chapter 3. Evolution of a New Axton 40

3.1 Measures for Recursive Functions 40

3.2 Measures for Primltive Recursive Functions 45

Chapter 4. Conctusion 53

4.1 General Remarks 53

4.2 Direction of Future Research 54

B1b110graphy 


\title{
UNSOLVABILITY CONSTDERATIONS
}

Ix

COMPUTATIONAL COMPLEXITY

\author{
Forbes Downer Lew18, Ph.D. \\ Cornell Unsuersity, 1970
}

\begin{abstract}
The study of Computational Complextty began with the Lnvestlgation of Turlng machine computations with limlts on the ancunts of tapc or the which could be used. Later a set of gereral axloms for measures of computation was presented and this instipated much study of the properties of these genersl measures. Anny intercsting reguleg were shown. but the qanerel axloms allowed measures with undeslrable propertles and several attempts have been made to tighten up the axinn:s bo that caly cestrable measures w11 bo deflaed.
\end{abstract}




\section{CHAPTER 2}

\section{Introduction}

\subsection{General Background}

The alm of computatlonal complexity ls to elassify and study the functions whlch are computable (or recuralve). Thlo is usually done by placlng them into some context using an Important characteristlc of the function.

Sub-recurslve hlerarchles vere E1rst used to divide these functions into classes and exhiblt some of thelr properties. Examples of this ere Grzegorczyk's hlerarchy of the prinltive recurslve functions [i] ard the nested recuralve functions of Péter [15]. These mothods classify functions by thelr structure, flaclag 11m1ts on the operations which are used to bulld functions.

An Intultive characterization of the pinltive recursive functions is the loop program hlerarchy devised by Meyer and D. Rltchle (12). A loop program is made up from comblnations of the lnstructions:

$$
\begin{aligned}
& x=x+1 \\
& x=0 \\
& x=7
\end{aligned}
$$

enclosed in loops which are denoted by the palr of 
Instructlons:

\section{LOOP X}

R:LLOOP.

The assignent Instructions are Interpreted as in any gtandard programing language and the loop Instructions cause the sezment between them to be executed $X$ times. The prinfive recursive functions are then placed In classes according to how many nested loops are requlred to compute them. Thls concept is formallzed: Definition: The class of functions requiring n loops: $L_{3}=\{f \mid$ There 18 a loop program whlch computes f with loops nested to depth $n$

A corplete history of sub-recursive hlerarchies and sore regults concerning them are concalned in [4]. In Automata theory the recurstive functions were classlfled by linlting the basic resources used in computation. Thls resource-bounded complexity began with the consideration of Turing machine computations uslag a limlted amourt of tape [13.20] or time [8]. All of the recursive functions were placed in complexity classes according to how difflcult they were to compute, or how much of a "natural" resource they used. For time of computation these classes are deflaed as follows. 


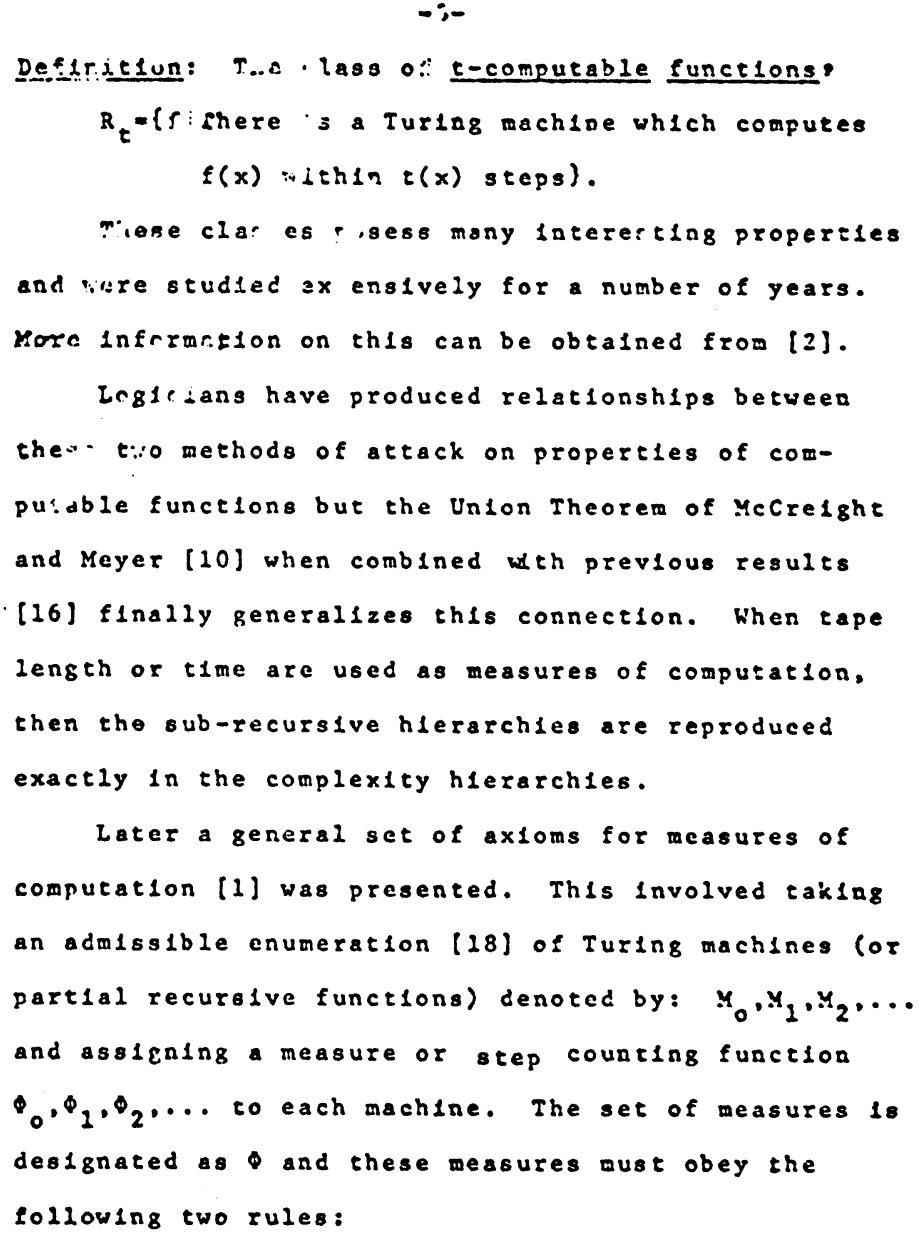


1) $x_{1}(x)$ hal:s $\Leftrightarrow \theta_{1}(x)$ halts

2) Thern is e recursive function $C$ such that for ai: $1, m$, and $n$ :

$$
c(1, n, n)=\left\{\begin{array}{l}
1 \text { if } \phi_{1}(m)-n \\
0 \text { otherw1se }
\end{array}\right.
$$

This first axion Indicates that whenever some function computes a value, then a cost of computation can be associated with 1t. And according to the second rule, the question "Does it cost n to compute $M_{1}(m)$ ?" Is always recursive.

These axions allow a very general set of deasures for whlch many interesting results have been derlved. The complextry classes formed from the general measures have been studied extensively in regard te thelr structural $(10,3)$ and naming properties [2]. Also the propertles of operatoro (5.11) have been noted. Unfortunately. many of the neasures allowed under the axtoms are so general that not all of the Intultively derlvable properties are preserved. Under time and tape as measures, complexity classes are recursively enumerable (r.e.) but measures can be defined so that some of the classes are not. other properties such as finite invariance and Infialteness are not preserved by reasures elther. 
Therefore sr:: condltion wust be added to the orlglnal two axicre so preserve propertles throughout the complexity cissses and 1 possitle, to ellmiate the indesirable froperties. It is reasorable to expect complexity classes to be r.e. and to cosfora by possessing the same propertles. Thls notion wlll be formallzed below.

\section{2 outilne of Thes1s}

Thls chapter contalned bylef outline of the progress in corputational complexity up to thls polat. A complete review of the literature is not inciuded since thls has been done elsewhere $[2,4]$.

In chapte: two: several properties of copplexity classes and sazs associated with them are studled. Aal open probicg in complexity: the erumerablitty of complexily ciasses, is elnally seteled by exibleton of measure which contalns complexity class that 1s :ot erume: able. Several Impllcations and general$123 t \ldots \%$ of thls inct are wentioned a:so.

ilext $5:$ Index sets of the time and tape complexity clasos: are found to be in the same recursice 1somorpl.: : : $5: \because$. Since thls insures that they all posess exact: the rame properties, this is taken =0 be a criterion for "netural" measures and called 
confcrmlty. Segszr: sets assoclated with measures are then studiac actording to conformlty and general zeasures are fcund to differ renarkably from the natural measures such as tape length or time of computation. The chapter ends with some general results on ilnies and iadependence of several kinds of conEor=1זy.

In chapter three, restrictions ln addition to the two axloms are placed on measures unt 11 the Deasures conform. This 13 done for both the recursive Eunctioss and the primltive recursive functions.

For the conventence of the reader the pages where wost of the notation and definitions first appear are g1ven below.

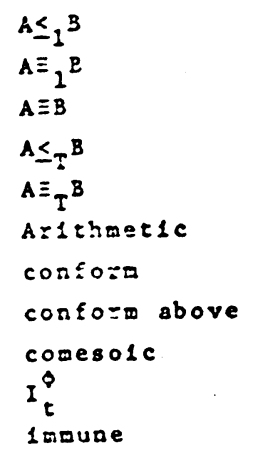

S6Bound

19

16

SEven 45

15

$\Omega \underline{\underline{\ln S u r}}$

45

16 Rzero

45

16

0

$170_{1} 3$

23

$\pi_{n}$

18

31 presentation 10

14 productive 14

$27 \quad R_{t}$

1 ninuae

14

9 


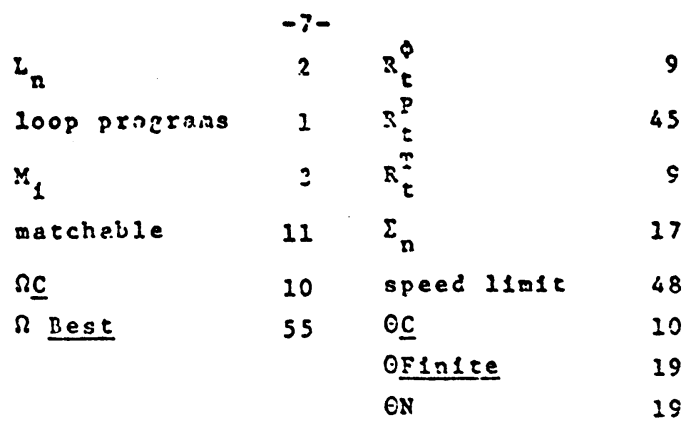

Some of the notation concerning functions must be Introduced at this polnt. The partial recursive functions are usually denoted: $\phi_{0}, \phi_{1}, \ldots$ where each $\phi_{1}$ refers both to the function computed and the particular algorithm In the enumeration of the functions. Naturally thls enumeration must be adm1ssible [18]. The symbol $\phi$ is used so that no particular scteme for computing the partlal recursive functions w1:l be lmplled in the results. In the materlal which follows a particular enumeration: the Turing machincs $M_{0}, M_{1} \ldots$ 1s used. All of the results are valid for any admissible enumeration of the part1al recurstive functions however.

Equality 1 s used gulte freely below and is deflned as follows. For total recursive fand 8 :

$$
\begin{aligned}
& f-g \Leftrightarrow \forall x[f(x)-g(x)] \\
& f-M_{1} \Leftrightarrow \forall x\left[f(x)-Y_{1}(x)\right] \text { and } \\
& M_{1} 18 \text { total recursive }
\end{aligned}
$$




$$
\begin{aligned}
& -8- \\
& M_{1}=Y_{f} \longleftrightarrow \nabla x\left[Y_{1}(x) \text { halts } \Rightarrow M_{f}(x)\right. \text { halte } \\
& \text { and } \left.x_{1}(x)=x_{f}(x)\right\} \text { and } \\
& \forall x\left[Y_{1}(x) \text { halts } M Y_{f}(x) \text { halts }\right] \text {. }
\end{aligned}
$$

Al1 this means is that equality between functions or machlnes Inplies that both are exactly the same function. To Indlcate ldentical machines equality between their indices will be used. 
CRAPTER 2

State of the Art (with two Axloms)

\subsection{Complex1ty ciasses.}

Most of the interesting results in conoutational complexity have been about the complexity classes or the classes of t-computable recursive functlons. These classes are deflned as follous:

Deflndtion: The class of tconputable functions 18: $R_{t}^{0}=$ (total fl there is sore $x_{1}=f$ such that $\theta_{1}(x) \leq t(x)$ almost everywhere\}.

(when 0 is time then $R_{t}^{T}$ will cenote these classes and $R_{t}^{L}$ wlll be used for tape $l \in n g t h$ as a measure). These classes have been studied in detall for time and tape as measures $[8,20)$ and sose of the deslrable propertles which were fount carry over to complexity classes deflned from general neasures. When measures were restricted slightly. then gore propertles of the natural measures carrled over. One Important property of complexlty clesses under the "natural" measures was the fact that the classes were r.e. [8]. In [21], Young wondered if this was true for classes cefined from general measures. Regretfully it is not, and this result 
Is presented here at also has teen shown independently by Robertson and Landweber [17]. Before this can be shown, however, some preliminarles are in order. To describe classes and thelr members more Ineulelveiy a set of alzorithms for computing them sust bc given. Th1s set "presents" the class and 18 dcfined:

Defincticn: The set A is a presentation for the class C Iff $A$ contains an lndex for each member of $\underline{c}$ and all $e l \in$ mexts of $A$ are indlces for members of $\underline{C}$, or $\underline{C}=\left\{f\left\{\tilde{I}\left\{\left\{1 \in A \wedge x_{1}-f\right\}\right\}\right.\right.$

The presentation which Immediately cones to mind is the complere presentation or inder set for a class.

Definle1on: The set A is the lndex set for the class C 1ff:

$$
A-\left\{1 \mid M_{1}-f \in \underline{C}\right\} \text {. }
$$

Csually the 1ndex set for the class of functions $\underline{C}$ w111 be designated $\Omega \underline{C}$. ( $\Omega \underline{C} 18$ uscd for classes of functions rather than $\theta \underline{C}$ since $\theta$ has becn used lin the liecrature for classes of sets.)

Defingtion: A class lo r.C. Iff lt has an r.o. presentation. (Thls means that the class 10 also 
recurslve v1a the well known "padding" trick).

An Interesting type of class is one where an algorlthm for any member of the class can be matched with an element of some standard presentation for the class. These classes are used below and are defined as follows.

Deflnition: C is a matchable class iff there is a recurslve $g$ and recursive presentation $A$ such that: $1 \in \Omega \underline{C} \Rightarrow g(1) \in A$, and $M_{1}=M_{g}(1)$.

Examples: a) Const-ithe constant functions\}. Let $A=\left\{a_{0}, a_{1}, a_{2}, \ldots\right\}$ where $v_{x}\left[v_{a_{k}}(x)-k\right]$ and for any $x$ define $g(1)=a_{y_{1}}(x)$.

b) $C-\left\{f_{n}\right\}$ for some recursive set of functions such that $\forall x\left[f_{n}(x)<f_{n+1}(x)\right]$. (e.8. $\left.f_{n}(x)=n x\right)$.

c) $C=\left\{f_{n}\right\}$ for some recursive set of functions such that $d k \forall n \forall x>k\left[f_{n}(x)<f_{n+1}(x)\right]$. (Functions bullt from polynomlals of degree n would be of this type).

Now a measure will be constructed using a matchable class so that an $R_{t}^{0}$ from th1s new measure 18 not r.e. Any of the examples will work, but (a) 
will be used for reasons of clarity.

Theorem 2.1: For any recursive there 1o a measure $\hat{i}$ such that $R_{t}^{\hat{\phi}}$ is not r.e.

Proof: Let $A-\left\{a_{0}, a_{1}, \ldots\right\}$ be a recursive presentetion of the class Const where for all $x, M_{a_{k}}(x)-k$. Then for any measure 0 , consider:

$$
\hat{\theta}_{1}(x)=\left\{\begin{array}{c}
0 \text { if } 1-a_{k} \text { and } y_{k}(k) \text { does not } \\
\text { halt in } x \text { steps } \\
t(x)+\phi_{1}(x)+1 \text { otherplse }
\end{array}\right.
$$

yote that $R_{t}^{0}=R_{0}^{0}$ and $x_{a_{k}} \in R_{0}^{0} \Leftrightarrow M_{k}(k)$ never halts.

Two things nust be shown in order to prove

the theorem. $\hat{\theta}$ must be cemonstrated to be a neasure and the non-enunerability of $R_{t}^{\hat{\phi}}$ must be shown. Th1s proceeds as follows:

a) $\hat{\phi}$ is a measure since:

1) $\hat{\phi}_{1}(x)$ hales $\Leftrightarrow M_{1}(x)$ halts since all $M_{a_{k}}$ are total and 18 measure

2) $\hat{c}(1, m, n) \equiv \hat{\Phi}_{1}(m)-n$ is recursive since 1 can be described: 


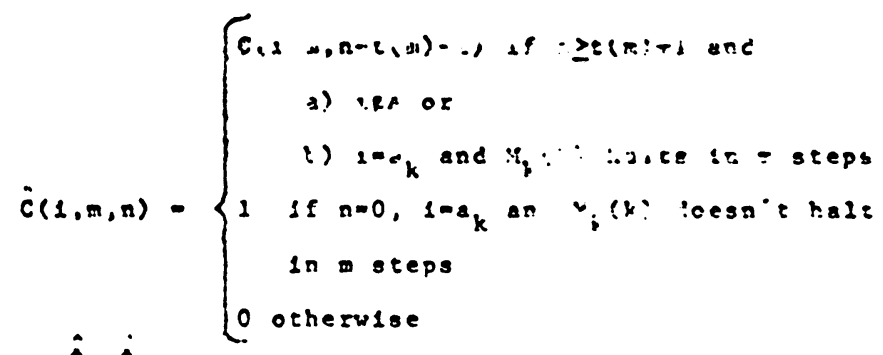

b) $P_{t}^{\dot{0}}-R_{n}^{\dot{Q}}$ is not r.e.

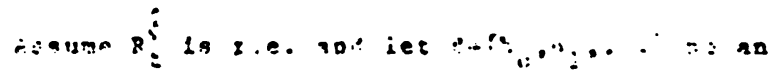

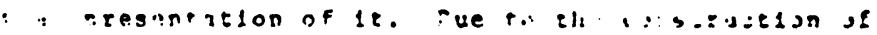

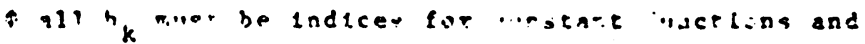
In inc: :

$$
\because i_{1}(x)-i k x_{v_{1}}=x_{v}
$$

Iierefore the sot $\left\{a_{y_{b}}(x) \cdot{ }^{a} y_{b_{1}}(x) \ldots\right\}$ in an r.e.

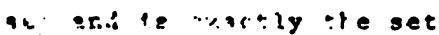

$$
\therefore \because q_{k}(k) \text { never tastaj. }
$$

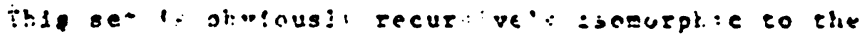
veil hrowe oct $\because-\left\{r_{1} \mid x_{k}(k\right.$. ever 132 ts $\}$ which Is not a.e.

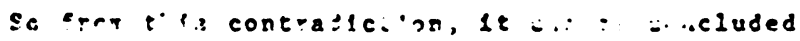
that $R_{t}^{0}$ in ane $: .$.

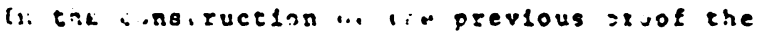
productive set $\dot{k}$ was used in orde: tr rruouce a non-r.e. 
class of total functions. Thls particular class of functions happens to be a productive class, ot moze foralily as in Dekker and Yyhill [6]:

Detinltion: C is a productive class iff there is s recursive f such that for every r.e. presentation $W_{1}$ of a subclass $D$, the set $W_{f(1)}$ 1s a presentation $0 \leqslant$ a class in $\underline{\underline{C}}-\underline{D}$.

in other words the function f provides a witness to the fact that the class $\underline{C}$ is not an r.e. class. other kinds of non-r.e. classes are the Immune (do not coztain ary. Infinite r.e. subclasses), and cosesolc (nelther productive nor lmane) classes. By seiecting the proper set (In place of $\bar{K}$ ) an lacune or comesolc class $R_{t}^{Q}$ could be formed. Another interesting aspect of the construction 18 that if $\hat{o}$ had been formed from $\theta=t 1 m e$ then $\hat{\phi}$ would have aany natural propertles but not 211 of the complexlty classes would be r.e.

This non-enumerablitiy of complextty classes polnts out one of the problems of general measures. So 1Fportant propertles are possessed by all complexity classes of all weasuras. In order to remove pathologles from complexity classes and loolate the 
"noturaf" measures 1t seems that properties sust be unlform throughout the complexity classes. The remalning results hopefully help to provide this und formity.

\subsection{Unsolvab111ty Prel1minar1es}

Most of the Important properties in Automata theory are preserved under isoserphisms. These are the recursively invarlant properties, and when sets are classifled under recursive lsomorphisis. all the sets in any 1 somorphism type possess the same properties. These concepts are defined:

\section{Definition: $P$ is a recursively invariant} property lff for any $1-1,0$, to, recurstive function $f$, If the set A has $P$ then so does $f(A)$. Properties such as recurstve entrerability and most cardinality properties are recursively Invariant. In order to study sets effectively they should be grouped by the properties they possess. The obvious classiflcation is by equivalence under recuralve isomorphisms.

Defln1tion: A is recursively 1sonorghic.to B ( $A \equiv B$ ) Iff there 18 a $1-2$, onto, recursive f such that $B=f(A)$. 
(The function $f$ is also known as a recursive permutatson)

3y theorem of xyh111 [14], the 1somorphism types (sets equivalent under 1somorphisms) are the same as the equivalence classes (or 1-degrees) under. 1-1 reduclbility. The refaclbllitles used here are defined as follows.

Eefinition: A is $1-1$ reductole to $B(A \leq, B)$ iff there is a 1-1, recursive function 8 such that for all $x$ :

$x \in A \leftrightarrow g(x) \in 3$

Definltion: A is $1-1$ equivalent to $B\left(A \equiv_{1} B\right)$ iff $A \leq{ }_{1} B$ and $B{ }_{1} A$.

Defln1t10n: A 1s Turing reduc1ble to $B\left(A S_{T} B\right)$ iff there is a Turing machine whth $B$ written on one tape which can decide membership in $A$.

Defirition: A 1s Iuring equivalent to $B\left(A \equiv_{T^{B}}\right)$ iff $A \leq T^{3}$ and $B \leq_{T} A$. Hierarchles which result from the reduciblilties outlined above can be used to describe sets very precisely, but almost no Intultive information about 


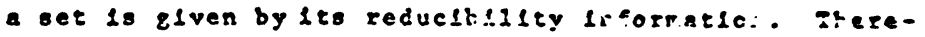
fore another hlerarchy, the Arlthmetlcal Rlerarchy, v111 be used in congunction with the 1-deprees. Th1s hierarchy reflects the structure of a set according to the number of alternating cuantiflers in the exnression of 1 ts membershlp problem. The membership problem for a $\Sigma_{n}$ set will begln with "d" and contaln nalcerateIng quantiflers, whlle a $\pi_{n}$ set beglas with " Th1s 1s stated more formally os follows:

Definltion: A predicate is arlehmetical if $1 \mathrm{e}$ is congtructed from a recursive predicate by quantiflcation of number variables.

Definition: A set is arithmetical if it is of the form $\{x \mid F(x)\}$ for sore arlthwertcal predicare $P$.

The arthmetical sets are then pleced in the hierarchy by the structure of thelr zerbership predicates which can alwayo be expressed as a recursive predlcates with a preflxes of quantiflezo.

Deflnition: a) A predicate is in $\sum_{n}$ iff les preflr begins with 3 and contains $n$ alternating cuantiflers. 
b) A predicate is in $\pi_{n}$ lff lts preflx beglns with and contalns $n$ sternating quantiflers.

A pictorial representation of the Arthmetical HLerarchy appears below as flgure 1 . The lines slantlag down towards the rlght denote the upper boundarles of the $\Sigma_{n}$ areas, whlle the IInes slanting down to the left form the top of the $\pi_{n}$ oreas.

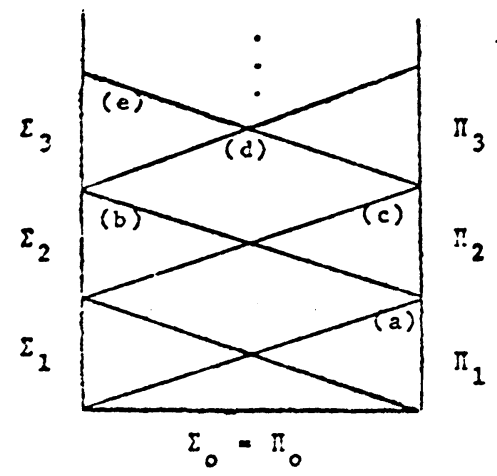

F18ure 1 
The intersection of $\Gamma_{1}$ and $\Gamma_{1}$ is where the recursive sets are found and 10 called $\Sigma_{0}$ or $\pi_{0}$. The r.e. scts all befong to $\Sigma_{1}$ and the lochtione of the following well kn wn bets are lndlcated in flgure 1.

a) $\theta \phi-\left\{1 \mid \mathrm{M}_{1}\right.$ never accepts $\}$

b! OFInIte $=\left\{1 / \mathrm{M}_{1}\right.$ accepts a flnite oet $\}$

$\therefore$ ON - $\left\{1 \mid M_{1}\right.$ accepts everything $\}$ - SIotal - $\left\{1 \mid x_{1}\right.$ 18 a total funcrion $\}$

d) sound - $\left\{1 /\right.$ the range of $M_{1}$ is bounded $\}$

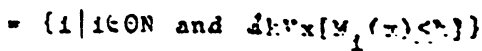

e) $\operatorname{\theta cof1n1te}=\left\{1 \mid y_{1}\right.$ arcepts a cosinite set $\}$ These sets arc all complete or waximal in thelr respective lncations in the hierarchy when ordered by 1-degrees. Only the proof for 2Bound will be given hera si:ce the others may be folnd in [9]. Fact: SBound is in $\pi_{3} \cap \pi_{3}$

Proof: a) Firat the prenex normal form of the membersh1p prosiem w111 be written out.

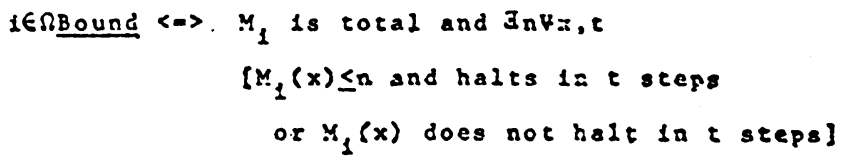

wh1ch can be eipressed as 3 yi: or VIV. Therefore Bound $\in \Sigma_{3} \cap \pi_{3}$. 
i) How RBound must be shown to be above $\Sigma_{2}$ (ox onintre $\leq 2$ Bound). This 1s done by taklng any $M_{1}$ and conseructing the machine $Y_{g(1)}$ :

$$
\begin{array}{r}
\because g(1)(x)=\text { the number of Inputs less } \\
\text { than } x \text { which } M_{1} \text { accepts } \\
\text { In } x \text { or lese steps. }
\end{array}
$$

Obplously if $M_{1}$ accepts a finite sat then $M_{g(1)} V 111$ be bcuried by the cardinality of that set and so: 150F1nite $\Leftrightarrow \&(1) \in$ Bound.

c) Finaliy Roound must be shown to be above $\pi_{2}$. Tris w111 be done by reducing or to 12 . Agaln, eklug iny nachlne $M_{1}$ consider $M_{g(1)}$ :

$$
M_{r(1)}(x)=\left\{\begin{array}{l}
0 \text { if } M_{1}(x) \text { hnlts } \\
\text { do not halt otherwise }
\end{array}\right.
$$

If $M_{1} 1 s$ a total function then $M_{B}(1)$ will compute the zero function (which is bounded), Otherwise $M_{g}(1)$ v111 be a pat1el function.

\subsection{A Crite: ion for Yeacurps}

Flest. the index seti of complexity clarges formed fron the "natural" seasure, will be classiflect. Thls w11 be done for time, fthe ingter of steps 1r. a 
computation). The proof nay be done more elegantly via two theorems in the next chapter but it is presented here to exphaslze that the r.e.-ness of $R_{t}^{T}$ and the fact that each $R_{t}^{I}$ costa1ns all finfte variants for some function are lafortart properties of time as a measure. This classificaton w1ll be used to suggest a crlterlon for measures and possibly to help find a method for strengthenIng the axpow?

Theorem 2.2: $\Omega_{R_{t}^{T}}^{T} \equiv$ Bound

Proof: a) $\Omega R_{t}^{T} \leq 1$ Bound

$$
\text { since } r_{t}^{T} \text { is an r.e. elass . } 8 j \text { for time as a }
$$
measure, let $A=\left\{a_{0}, a_{1} \ldots.\right\}$ bo a $y . e$ presentation for $R_{t}^{T}$. Then for any $U_{1}$ deflae the machlne $M_{g}(1)$ as f0110\%8:

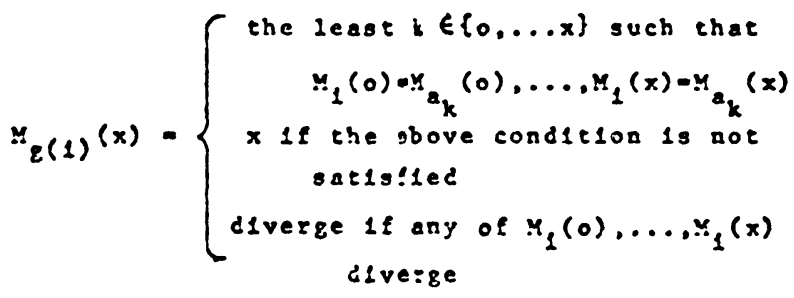

Therefore if $1 \in \Omega R_{t}^{T}$ then fer some $a_{k} \in A, M_{1}-M_{a_{k}}$ and so $V_{x}\left[M_{g}(1)(x) \leq k\right]$. If trin then no $a_{k}$ 
w11 be founc and so $M_{8}(1)$ w111 be unbounded. Thus:

$$
1 \in \Omega R_{t}^{T} \Leftrightarrow 8(1) \in \Omega \text { Bound. }
$$

b) $\Omega$ Bound $\leq_{2} \Omega R_{t}^{2}$

For any r.e. $R_{t}^{q}$ there 18 a function b which majorizes the class [2!. Also, every $R_{t}^{I}$ contalns at least one fuaction and all lts finlte varlants. Therefore, select some in $R_{t}^{T}$ so that all of 1 ts flate varlants are also in $R_{t}^{T}$, and for any $M_{1}$ deflne:

$$
M_{g}(1)(x)=\left\{\begin{array}{l}
f(x) \text { if } g_{1}(x) \leq \max \left[M_{1}(0) \ldots \ldots M_{1}(x-1)\right] \\
b(x)+1 \text { if } M_{1}(x)>\max \left[M_{1}(0) \ldots, M_{1}(x-1)\right] \\
\text { diverge :f any of } M_{1}(0), \ldots, M_{1}(x) \\
\text { diverie }
\end{array}\right.
$$

Iterefore $Y_{q(1)} 18$ cotal if $Y_{1}$. Is total, and $1 f M_{1}$ 1s bounded then $M_{g}(1)$ will le a finlte variant of $f$ and therefore a function $1 \mathrm{n}:$ :

Fros thls theorem and a cesult of McCrelght and Yeyer $[10\}$ whlch states hat fre potfme there is a t such that the loop prigram class $I_{n}$ is exacely the same as $R_{t}^{T}$, the followin; result way be oasily provea. 
Corol11.xy: $\Omega L_{n} \equiv \Omega$ Bound.

An Inceresting property of time as a measure 18 Indlcatid by thls theorcm. All of the Index sets of the conplexity classes fall into the same 1-degree; In fact, the 1-degree of RBound. This means that all of tile $\Omega K_{i}^{T}$ and $\Omega R_{t}^{T}$ posses exactly the same propertles. Ti:e ̈̈ollowing condltion o. messures is suggested by this fact.

Definltion: $\$$ conforms (on $S R_{t}^{\phi}$ ) iff for al1 recursive $t_{1}$ anc $t_{2}, \Omega R_{t_{1}}^{0} \equiv \Omega R_{t_{2}}^{0}$.

Th1s definfticn can be easly extended co Turingreduciblitty in the obvious manner. (SInce all Index sets acc cylinders, w-confomity ls equivElent to l-conformlty.)

\subsection{Index sets of Complextty classes}

Now the Index sets of the complexity classes $\left(\Omega R_{t}^{3}\right)$ for zcasza! measures will he riassified by the: $x$ degrees o: unsolvab1l1ty. The orily posiclve result in this scction 18 that all $S_{t}^{0}$ fall into the same Turing degree of unsolvability and this is shown b: low. 
Theores 2.3: Every 1 -conforms (on $\Omega R_{t}^{\phi}$ ).

Froof: The "osacle machine" Mrgquel which has:

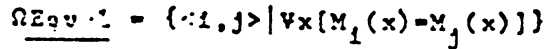

$$
\begin{aligned}
& \text { (or } 311 \text { palrs of lientical gachines) }
\end{aligned}
$$

writen on 1 ts reference tape will be used in this proof. Toual is a well knorn $\Pi_{2}$-cumplete set. and thestore can decide membershlp froblems in the Turing-degree containing (b), (c), ard (d) In Figure 1.

Also, the following two presentations are used:

$$
\begin{aligned}
& A=\left\{a_{c}, a_{1}, \ldots\right\}=\text { presentation of } R_{t}^{\phi} \\
& B-\left\{b_{0}, s_{1} \ldots \ldots\right\}-\text { presectation of } P R-R_{t}^{\phi}
\end{aligned}
$$

where $P R$ is the class of all ;artlal zesurslve functions. The se: $A$ use: tone will be dnflncd later as $I_{t}$, whlch 1s $\Sigma_{2}$ set. Robartson and Landweber have shown the set $B$ to be r.e. [17]. Therefore both $A$ and $B$ can be enumerated or listed by $\mathrm{M}$ Egual.

Tris machine operates (when glven 1rput i) by I1sting the sequence $a_{0}, b_{0} a_{1}, b_{1}, \ldots$ and shecklng the palrs $\left\langle a_{0}, 1\right\rangle,\left\langle b_{0}, 1\right\rangle$, etc. against the pa:rs on the reference isst. 
Sooncr ir la:er some $\left\langle a_{m}\right.$, 1$\rangle$ or $\left\langle b_{n}, 1\right\rangle$ w 111 match a pals or, the reforence tage and then the machlac halts and outputs:

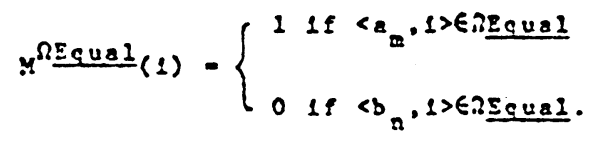

Therefore $\Omega R_{t}^{0} \leq_{T} \Omega E_{\text {cual }}$ and elnce $\Omega$ Ecual $\equiv \theta \leq_{1} \Omega R_{t}^{0}$ (whown below), the result followg.

The previous theorer is oulte frteresting becasse 1 shows that all $\Omega P_{t}$ are consined to the Iurlag cegree of (b), (c), and (d) on the chart Elven earlier. Also It Indicates that with the orlginal axlors the index sets for the complextey classes gonform in a rouft way. Unfortunately Turing-reduc1b111:\% 1s rather cruce and allows sets whth differlag propertles to be lncludec vithin lts degrees. On the other hand, 1-reducibllity 18 much otricter and as was pointed out above, sets la the same l-degrec possess the sare recursively 1nvariant properties. If all measu.es oossesse? 1-conformity then pathological propertles mlght be excluced. However: qeneral measures do not cinform, and this fact ls shown in the following sequcnce of results.

Fact: For any recurstve function tand ree. class of 
cotal function.

$$
R_{t}^{\hat{\theta}}=\underline{c} \text {. }
$$

recof: Let $A=\left\{a_{0}, a_{1}, \ldots\right\}$ is an r.e. Fresentation of the cless $C$ and be any measure. The meperure $\hat{s}$ Is desined:

$$
\hat{s}_{1}(x)=\left\{\begin{array}{l}
0 \text { if } 1 \in\left\{a_{0} \ldots \ldots a_{x}\right\} \\
e(x)+\theta_{1}(x)+1 \text { otherwieb }
\end{array}\right.
$$

Obvlously $\hat{t}$ is measure (since is a mensure and $t(x)$ is recursive) and $R_{0}^{0}=R_{t}^{0}-C$.

Corollary: There are measures $*$ ihtch do not conform (os $\left.2 a_{t}^{\natural}\right)$.

Proof: Immediate from the above fact and the existence of r.e. classes of total furctions whose lindex sets are not in the same l-dergee. (For example sBound and (Cosst $\equiv \theta N)$.

These results polnt out sone differences between index sets for cooplextey classes. The $T$-conformlty theoreo Irdicates that if a Turinp machine is glven L Lasine of an index set for one comolextty class then it can cencrate the Index set: for any cther slase. If the natural measures are used then this can be done by a recursive function. 


\section{5 ocher Sets in Complexply Theory}

Another Interesting set defined from measures

18 the set of algorlthms which are t-computable;

the efficient presentation for $R_{t}^{0}$.

\section{Definition: The set of t-computable algorithms is} defined:

$$
I_{t}^{0}-\left\{1 \mid M_{1} \text { 1s total and } \theta_{1}(x) \leq t(x) \text { a most everywhere }\right\} \text {. }
$$

This set is contained in $\Sigma_{2}$ since lta membership problem 1s easlly witten in $\Sigma_{2}$ form as follows.

$$
\begin{aligned}
& 1 \in I_{t}^{\phi}<>\phi_{1}(x) \leq t(x) \text { s dmost eve-ywhere } \\
& \left\langle\rightarrow \operatorname { s i n } \left[\forall x\left(x>0 \Rightarrow \theta_{1}(x) \leq t(x)\right)\right.\right. \\
& \left.\wedge V_{x} \leq n-z\left(x_{1}(x) \text { halts } 1 r=\text { stegs }\right)\right]
\end{aligned}
$$

Thlo 18 obviously a $\Sigma_{2}$ form since bounded quantflers can be eliminated.

When tape and time are usec as measures, the $I_{t}^{0}$ for $t(x)$-constant are recursive (this allows minlmal growth rate (2]), while for increasing $t(x)$, It becomes $\Sigma_{2}$-complete (or $I_{t}^{\phi} \equiv \theta$ Finlte). By sisht modification both of thase measures can be forced to

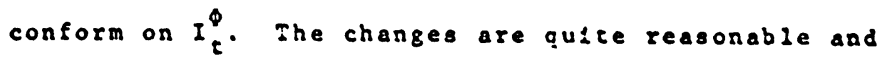
Involve making each machlne read or copy 1 ts input. 
The following theorem is proven for tape length but the can be usod also.

Theored 2.4: For $\mathrm{Y}_{1}$ which copy thelr Inputs, I con. forms (on $I_{t}^{2}$ ).

Proof: The construction of the membership problem for $I_{t}$ shown above indlcates that $I_{t}^{L}$ is $\ln \Sigma_{2}$ and therefore $I_{t}^{2} \leq 1$ OFInite.

In order to prove conformlty on $I_{t}^{2}$ then the reduction: Orinite $\leq I_{t}^{L}$ must be demonotrated. Thio reduction of eFlnite to $I_{t}^{2}$ ls achleved by constructing aachine $M_{g}(1)$ whlch coples down lts input, then slaulates $X_{1}$ upon this anount of tape. If $M_{1}$ accepts anything new, then $M_{g}(1)$ exceeds $t(x)$ tape. Therefore. if $M_{1}$ accepts a flnite set, then $M_{P}(1)$ steys within the anount of tape the Input takes up almost everywhere.

More forraliy, this 1 s done by taking any $M_{1}$ and constructing $:_{g}(1)$ such that: when given an Input

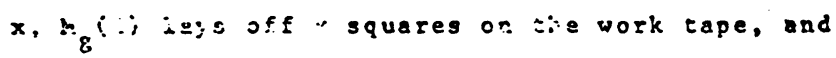
sinulates $M_{j}$ on eacil of the inputs $0, \ldots, x$ until for each one:

a) X steps of the sompu:. $1,1, \therefore$ : 2 been comDieted o: 
b) $M_{f}(x)$ halts or

c) $M_{1}(x)$ requires wore than $x$ squares of tape.

Then $1 f x_{1}$ he:ts on some laput for the flrst sire. $M_{g}(1)$ uses more tiren $t(x)$ amount of tepe. Otherwise $Y_{g}(1)$ heles.

Therefore:

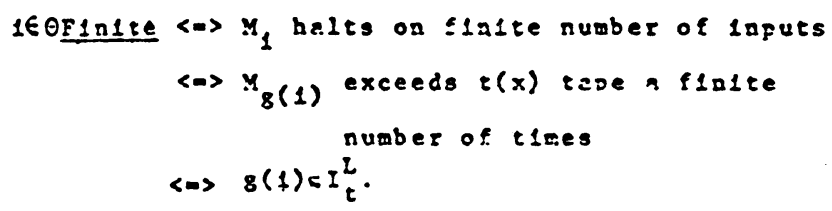

Since thre are measures which have ocursive end $\Sigma_{2}$-complete $I_{t}^{0}$ even $T \cdot \operatorname{conform} 1 \mathrm{y}$ lo out of the quastion for general measures. In fact, as the next sequence of results shows, the $I_{t}$ ara sprend out through $\varepsilon_{2}$.

Lemma: Por any set $A$ and infinite, recursive set $B=\left\{b_{0}, b_{1}, \ldots\right\}$ the set

$$
C=\{b, \mid 1 \in A\}=m_{m} \cdot
$$

Proof: a) $A_{-i} c$ vln $g(x)=b x$

b) Assume thet eq and then $C \leq A$ via:

$$
g(x)=\left\{\begin{array}{l}
z \text { if } x: 3 \\
-1 \text { if } x=b /
\end{array}\right.
$$

and therefore $C \equiv A$. 
Iheoren 2.3: For any recursive t and r.e. set $A$ there 18 a measure $O$ such that $I_{t}^{0} \equiv_{m} A$.

Proof: Select as lnflate set $B=\left\{b_{0}, b_{1}, \ldots\right\}$ soch

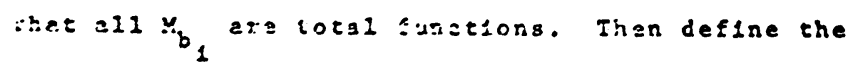

r.e. set $C \equiv_{\text {m }} A$ S $=0 ; \because$ he $\therefore \because$ s.

Let $c-\left\{\dot{r}_{0}, c_{2}, \ldots\right\}$ and for ary $\$$ deflaes

$$
\hat{\theta}_{1}(x)=\left\{\begin{array}{l}
0 \text { if } i \in\left\{c_{0}, \ldots, c_{x}\right\} \\
\sigma_{j}(x)+t(x)+1 \text { otherwise }
\end{array}\right.
$$

$\hat{\phi}$ is a Deasure elsce $t$ s a recusive function,c is a r.e. set, $2=0 \$ 18$ a measure. Also, from the lexsis:

$$
I_{t}^{0}-c \equiv A
$$

An extension of the techniques used in theorem 2.2 and 2.5 cen be tsis ser oroduce a measure where for every m-degree in $\Sigma_{1} U \pi_{1}$ tirere 18 sode touch that $I_{t}^{O}$ is in that m-degree. Th:s gives a rather ugly, layered structurn to $c h=$ inplexlty clnsoes.

\subsection{Conform1ty Relationships}

Even though wessures exist with 1rregularities or undesirable propertles, these flieronena exist only 1s the corplexity classes et the bottow of the hlerarchy. Aa example of this is that as soon as the functlons of 
Enlte support become t-computable (as thes must ooner or later), then the complexity classes become r.e. [2]. As one would expect, ali measures eshible conformtey above some point in the complexisy hlerarchy.

Definltion: conscrms tbave to (on $\left.\Omega_{t}^{\circ}\right)$ iff for all

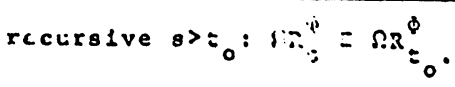

Theorem 2.6: For every there 18 a recursive function $t_{0}$ such that o conforms above $t_{0}\left(\mathrm{cn} \Omega R_{t}^{0}\right)$.

Proof: The cerered $t_{0}$ is that such that $B_{t_{0}}^{0}$ contalns the functions of finlte support. Then the proof proceeds like Theorem 2.2 .

In order to show conformity on $I_{t}^{\phi}$ the recursive relativity between ceasures (due to BIun (1]) is required.

Theorem 2.7 (BIum): Fur any measures and $\hat{\theta}$ there is a recursive iniction foch that for almost a.1 $x$ and all 1:

$$
\theta_{1}(x) \leq f\left(x, \hat{\theta}_{1}(x)\right) \text { and } \hat{\theta}_{1}(x) \leq E\left(x, \theta_{1}(x)\right) \text {. }
$$


Theore= 2.8: For every the :e lo a recursive function $t_{0}$ such that conforms ciove $t_{0}$ (on $I_{t}^{\phi}$ ).

Proof: This p:olf proceace in ihe same manner as Itseorer 2.4 witl. the rciluad $f_{0}(x)=f(x, x)$ where $f$ is the function $1 \mathrm{n}$ the Iaenrem 2.7 with $\hat{\phi}=t a p e$. Thls fories the reletlonsitin:

$$
1 \in 0 ! \ln 1: g=>g(1) \in I_{f(x, x)}^{0}=I_{t}^{0} \sum_{T}^{0}
$$

In orce. to make the machine $Y_{g(1)}$ take more than $t_{0}(x)$ sizes in an r.e. rresentation for a class of to: functions contalning $R_{t}^{\circ}$ is selected and whenevi $=x$, eccepts a new input, then $M_{g(1)}$ computes a valt different from enother member of the presentatlor. Thus:

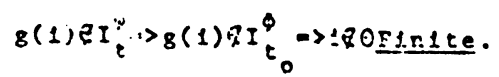

At flrst, one ilght expec: to flnd some relationship between the twc kinds of cinformlty which have been examined so Ear. A close ilok at time and tape length as wessures ravials that cinformity on $\Omega R_{t}^{0}$ coes not imply conformliy on $I_{t}^{Q}$. inds seens reasonable slace $I_{t}^{0}$ ranges ove: a larger irea than $\Omega R_{t}^{0}$. However the reverse of this is not tree elther and 1s denonstrated in the next theorem. 
Theorem 2.9: There is measu: intch conforrs on $I_{t}^{2}$ but does noc conform on $8 a_{t}^{*}$.

Proof: Let $\left\{z_{0}, z_{j}, \ldots\right\}$ be an $i n \leq 1 r-t_{e}$, recursive set of Indicles for the zero furction. Conslder the weasure which is reflned:

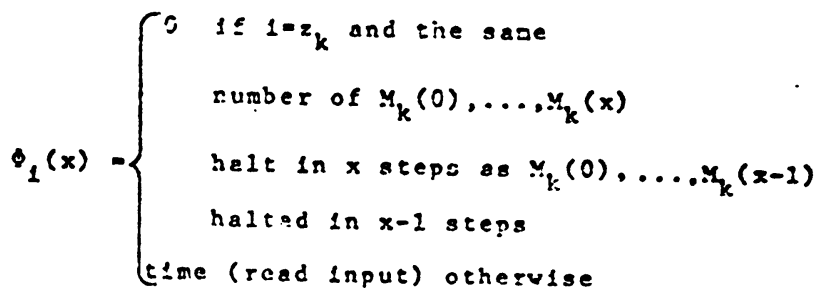

Obvlously $R_{0}^{\phi}-\{$ zern functlon $\}$ since no rachloe which reads its inlit cal operate in zero steps.

Also, since the zero furction can be computed In $x$ otepo, Sil of the remalning $R_{t}^{0}$ are the sase as time. Therefcre

$$
\Omega R_{0}^{0}-\left\{1 \mid \psi x\left\{M_{1}(x) r 0\right\}\right\} \equiv_{1} \theta N
$$

wh1le every other $\Omega R_{t}^{Q}{ }_{1} \Omega$. nunc. Therefore $\theta$ does not conform on $\Omega R_{t}^{0}$.

But does conform on $I_{t}^{0}$ and this is accomplished for $I_{0}^{0}$ by the following reduction:

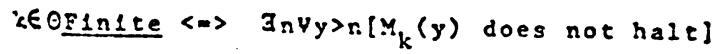

$$
\begin{aligned}
& \Leftrightarrow I_{n} \forall y>n\left[\Phi_{z_{k}}(y)=0\right] \\
& \Leftrightarrow z_{k} \in I_{0}^{\varphi}
\end{aligned}
$$


$A$ recursive function mapplng $k$ into $2_{k}$ 1s rather caslly found and so all $I_{t}^{b} \equiv$ GE1rite.

For natural reasures such as tape find the the set $I_{t}^{5}$ is $1-1$ reduclble to $\Omega R_{t}^{0}$. This seans that tisere is a recursive function which maps $I_{t}^{0}$ Into $\Omega R_{t}^{\$}$. This 13 sot true however for the measures constructed 10 theorers 2.1 and 2.9. Another 1rteresting aspect of tape and time (when inputs are read and copled) Is that both $I_{t}^{0}$ and $\delta R_{t}^{0}$ are in the same Turing degree of unsolvab121ty. The following reslogy points out some of the reasons for this. Urfortunately the converses are false and this $1 \mathrm{~s}$ easily seen by exacining sose of the previous theorems.

Theoren 2.10: For every measure $\phi, I_{t}^{\Phi} \leq_{T} \Omega R_{t}^{\Phi}$. Proof: Since $I_{t}^{0} \in L_{2}$ then $I_{t}^{0} \leq_{T} 0 \underline{\underline{L} \ln I t e}$ and as was

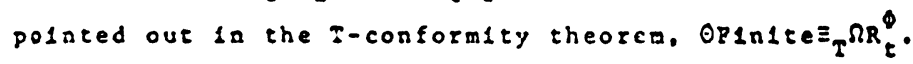

Theoren 2.11: If $\theta$ conforms (on $I_{t}^{0}$ ) then $I_{t}^{\phi} \equiv_{T} \Omega R_{t}^{\phi}$. Prcef: Conformity on $I_{t}^{0}$ 1molles that $I_{t}^{\phi} \equiv_{T}$ OFinite. Iheorem 2.12: If conforms (on $\left.\Omega R_{t}^{0}\right)$ then $I_{t}^{0} \leq 2 \partial R_{t}^{0}$.

Proof: Conformity on $\Omega_{t}^{0}$ implies that $\Omega R_{t}^{0} \equiv{ }_{2} \Omega_{\text {Bound }}$ and $\theta$ zinize $\leq_{1}$ roound. 
Since the work of Blum [1] the definlelor of complexity classes have been defired with an "almost everywhere" clause. This has been fustifled by stating that for mose natural measures, the classes are equivalent to those defined with an "everywhere" clause if output operations are lgnored. However there are some differences and scucral interesting facts are noted here.

Definftion: The class of t-computable functions:

$$
s_{t}^{\phi}-\left\{f \mid a M_{1}=f \text { and } \forall x\left[\phi_{1}(x) \leq t(x)\right\}\right\} \text {. }
$$

Definltion: The set of t-computable alsorlthms:

$$
H_{t}^{\phi}-\left\{1 \mid \forall x\left[\theta_{1}(x) \leq t(x)\right\}\right\}
$$

One thing which should be noted immediately is that $H_{t}^{\phi}$ is a $\pi_{1}$ set and $\Omega s_{t}^{\phi}$ (11ke $\delta_{t}^{0}$ ) is a $\Sigma \Omega_{3} \pi_{3}$ set. Severat other obvlous facts are stated ia the following corollary.

Corollary:
a) $H_{t}^{0} \leq_{1} \Omega s_{t}^{0}$
b) $s_{t}^{\phi} \subseteq R_{t}^{\phi}$
c) $H_{t}^{0} \subseteq I_{t}^{0}$

Most other correspondences betwecn the two definftions are false. There are measures and recursive tor which $H_{t}^{\theta} \leq_{1} I_{t}^{\theta}, I_{t}^{0} \leq_{1} H_{t}^{0}, S_{t}^{0} \leq_{1} \Omega R_{t}^{\theta}$, and 
Since the work of BIun [1] the deflnitlon of complextey classes have been ieflned with an "almost everywhere" clause. Thls has been fustlfled by stating that for most natural neasures, the classes are equivalent to those deflned with an "everywhere" clause if output operations are 1 gnored. However there are some differences and scveral lnteresting facts are noted here.

Definftion: The class of t-computable functions: $S_{t}^{0}=\left\{f \mid 3 x_{1}=f\right.$ and $\left.\forall x\left\{\phi_{1}(x) \leq t(x)\right\}\right\}$.

Definlt1on: The set of t-computable algorlthms: $H_{t}^{0}-\left\{1 \mid \forall x\left\{\phi_{1}(x) \leq t(x)\right\}\right\}$

One thlng whlch should be noted immediately lo

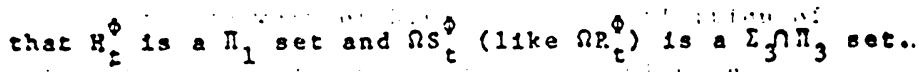
Severat other obvlous facts are stated in the E0110u!ng corollary.

Corollary:
a) $H_{t}^{0} \leq-18 s_{t}^{0}$
b): $s_{t}^{\phi} \subseteq R_{t}^{\phi}$
c) $H_{t}^{0} \subseteq I_{t}^{0}$

Most oshar correspondences betwean the two definftions are false. There are measures aid recursive t for which ${ }_{t}^{0} \leq_{1} I_{t}^{0}, I_{t}^{0} \leq H_{t}^{0}, \Omega S_{t}^{0} \leq 1 \Omega R_{t}^{0}$, and 
$\Omega R_{t}^{0} \leq 2 \Omega S_{t}^{0}$.

As before, there arc several linite on the 1rregularltses presirt in meesurcs. The foldovlag theorem corresponds to onveral frevlous resules.

Theorem 2.13: For any tirere are rocursive t 1 and $t_{2}$ such that:

a) $H_{t}^{\Phi} \leq 1 I_{t}^{0}$ for 211 t $>t_{1}$

b) $\Omega S_{t}^{0} \equiv S_{1} R_{t}^{0}$ for 211 t>: $:_{2}$

Ore of the Important questons in Automata theory has always been whethcr thengo are recursivels enumerable. However answerlng this quastion does not provicie much information, anc more specific atributen cí enumeration sust be stuclcd. In . [21], Young Looked at the speed of cruncratlon and provided some adjltional propersics of computarlon.

- Of Interegt here are the slatlonships betweea presentations of comple: ity classes and the eets of t-computable r.lgorlthms. The flrst rosult in this area was exhlolted by McCre1ght ard yeyer [10].

Theorer. 2.14: For ang there lo c riogrive s such that for sufficlently large there jo a subses of

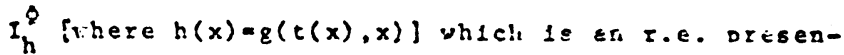


$\operatorname{cat100}$ of $R_{5}^{8}$.

For sore =easures thls furction 8 could concelvably. grow gul:e quickly, so these presentatlons way cortaln wany aigortehns which are nowhere near tcosputable. Sut viewed with a verblon of the Gap. Theored [2] an Imnediate corollary insures that sone complexity classes are presentable in t-compurable form.

Iheorea 2.15: (Weak Gap): For any and every recurslve 8 there are arbltrarily large tiuch that::

$$
I_{t}^{0}=I_{h}^{0}
$$

$\{$ where $h(x)-g(t(x), x)\}$.

Corollagy: For any there are arbltrartly large reoursive $t$ such that there is a subset of $I_{t}^{D}$ wh1ch is an r.e. presencation for 8.

The $:$ ext step $1 \mathrm{~s}$ to ask whether all weasures produce conislexity claeses whlch have no t.e. presentations that contalo only t-computable algorlthms. Ihls is not true, since Robertson and Landweber (17) produce an alsorlthe based upcr. [10] wilch generates r.e. subsets of $I_{t}^{L}$ which pranene $R_{t}^{L}$. Th1s proof (uleh minor modiflcatlons) is aiso valle for time ae - measure. 
Ar :ntart:tiag fact is that this result does not apply to $j_{t}^{i}$ and $a_{t}^{L}$. Thls 18 shown in the followlrg eçuence.

Lemma: If an r.e. preacntation for $k_{t}^{L}$ (or $s_{t}^{L}$ ) is a subset of $H_{t}^{L}$ then there 1 a very small recursive 8 suck that:

$$
R_{g+t}^{2}-R_{t}^{2} \neq 6 .
$$

Proof: Thls will be bastcally a diagonalization procedure. The function g mentlonce cbove vili be $g(x)=x$ for ald liputs $x$.

Let $A=\left\{a_{0}, a_{1} \ldots \ldots\right\}$ be the $=. e$. presentation of $R_{t}^{2}$ and let all $a_{k}$ be members of $I_{t}^{L}$. Then define the machine $M$ which will diacnalize over the complexity class $R_{t}^{L}$ ad follows.

When gresented with the infut $x$, the nachine $y$ :

a) Lays of $x$ squares of tape.

b) Producos the integer $k$ : the $x^{\text {th }}$ number in the seouence:

$0,0,1,0,1,2,0,1,2,3,0, \ldots$

c) Writes down a description of machine $M_{k}$ If this ls posalble within $x$ tape oquares. If not, then halis with an output of zero. 
d) If step (c) was completed successfuliy then slaulate $M_{k}$ on the tape adjoining the description end output a different answer.

This procedure abviously produces a function which is not in $g_{t}^{L}$ since sooner or later step (c) will be completed for every interer. Ih1s machine computes withIn $:(x)+x$ space $: 0=$ al1 inputs, so therefore $1 t$ is in $R_{t+q}^{2}$ where $g(x)=x$.

This lemma also holds for time as a mare rlth

a few minor modiflcatlons. When coupled with the Gap theorem the following result emerges.

Theoren 2.16: There are arbltrarlly large recursive c suct that no subset of $\mathrm{H}_{t}^{2}$ is an r.e. presentation of $R_{t}^{2}$.

Proof: Irsedste from the lemm and the Gap theorem.

It would seed reasonable to suspect that the last two results alght hold for general measures rather than only tape and time. This can be accomplished by application of the Biun relativity result whlch was siven as Theorem 2.7. 
Chaprer 3

Evolution of a New Axion

From the evidence in the last section ard in the 11terature 1 t could be assumed that the or1g1nel two axloms are too weak to characterlze the natural nessures of computatlon. Some new requirerent must be adced te the axloms in order to ellminate maaures usth undearable properties.

In this section constraints will be placed ufoa wesures to fcrce conformlty. Ihis is cone for the complexlty hlerarchles of recurslve functions anc primltive recurslve functions.

\subsection{Measures for Recurslve Functlong}

These results are suppested by Theorem 2.2 and progress eradually towards conformlty.

Theorem 3.1: If C 1s a non-empty class of total functions, then $O H \leq 1 \Omega$.

Proof: For some function $f \in \underline{C}$ and any machloe $M_{1}$ cons1der:

$$
u_{g(1)}(x)=\left\{\begin{array}{l}
f(x) \text { if } x_{1}(x) \text { hales } \\
\text { diverge otherwise }
\end{array}\right.
$$

Therefore $M_{g(1)}$ ls total and equal to f only $1 f M_{1}$ is total. 
os. sor forman:

$$
\begin{aligned}
& 1=0 \text { s } \Leftrightarrow \text { w }\left[M_{1}(x)\right. \text { halts] } \\
& \Leftrightarrow \|_{\vee}\left[x_{g}(1)(x)-f(x)\right\} \\
& \Leftrightarrow(1)(\Omega \underline{C} \text {. }
\end{aligned}
$$

When palred with the T-conformlty theorem (Theoren 2.3), th1s result provides maximal and minimal bourds for the $20 c a t 100$ of $\Omega R_{t}^{\$}$ in the artingetical blerarchy. Ihls 18 plctured in F1gure 2 and represents where the $\Omega R_{t}^{\hat{V}}$ are located for general neasures.

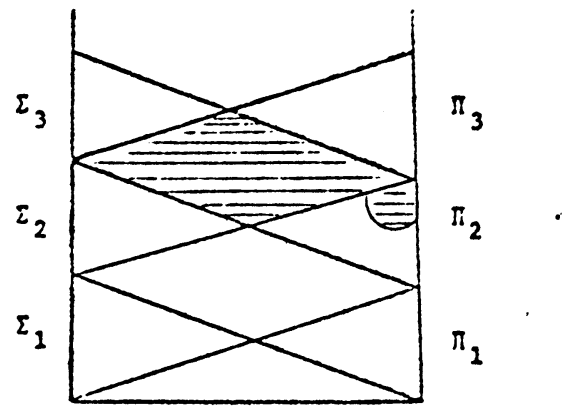

F1gure 2

The next sep 18 to reoulre that all complexlty classes be r.e., whlch seens to be a reasonable reatrlat102. 


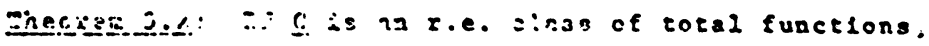

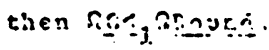

IEscr: is.. $4 . i_{2},{ }^{2}, \ldots$ be an r.e. presentation for the class $c$ sor for any $X_{1}$ define:

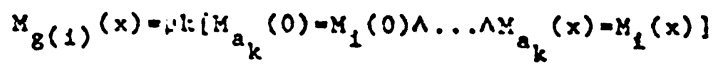

or equivalently, If $M_{a_{k}}$ ls the flrst machloe on the $118 t$ A which acts the same as $M_{1}$ on Inputs less than or equal to $x$ then set $M_{8(1)}(x)=k$.

obviously if $M_{1}$ is a function in the class $\underline{C}$ then some $M_{a_{k}}$ will be found to be the same as $M_{1}$ and

$$
V_{x}\left[M_{B}(1)(x) \leq k\right] \text {. }
$$

otherwloe machlnes further and further along on the $118 t$ will have to be examined and $x_{g}(1)$ w111 be unbounded.

Comblned with Theorem 3.1 , ehls result restricts the location of $R_{t}^{0}$ to the shaded area in Figure 3 . Conformlty has not been achleved yet, so just waklng the complexity classes r.e. does not seem to be an adequate restriction. 


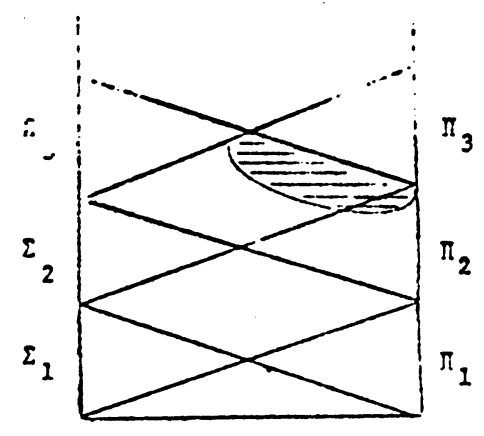

F1gure 3

Iheorem 3.3: If $C$ is an r.e. cless of total functione contaioing all findte varlationo of at least one funct10n, then Bound $\leq_{1}$ s.

Proof: Since $\mathrm{C} 18 \mathrm{r} . \mathrm{c}$. there 18 recursive b ouch that $f \in \underline{C} \rightarrow f(x)<b(x)$ almost everywhere. So if $f$ is the function whose fincte varlants are in $\underline{C}$, for any $x_{1}$ define: 


$$
\begin{aligned}
& -44-
\end{aligned}
$$

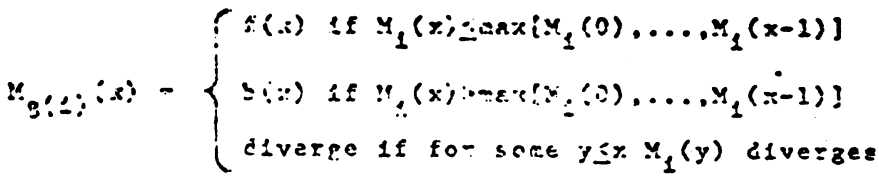

Thus 1: $x_{\text {. }} 13$ trieal then $M_{g}(1)$ is total and $M_{Z(1)}$ is a flalte varian: ci f lff $M_{1}$ ls bounded. More forgaliy:

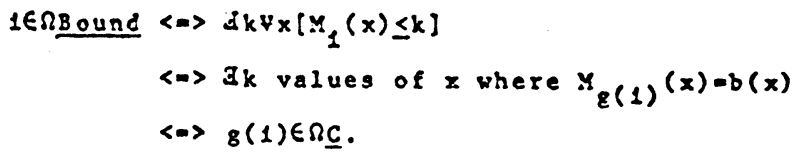

When these classes are complextty classes, then contalning finlte varlations $1=p$ lies recursive enumerab1l1ty. $\Omega R_{t}^{0}$ has been conflned to a slagle 1-degree as is shown in Figure 4. Of course this degree contalns all of the $\Omega R_{t}^{0}$ for tape and tre as measures.

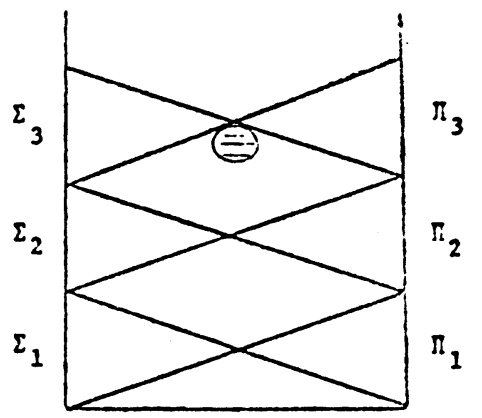

F1gure 4 


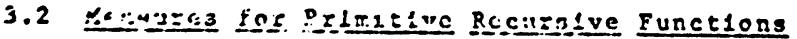

Ycth of the wozk in Autcrata incory has b,

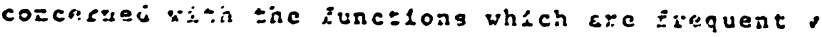
co=2used; sc: vith all of the comfutibia functions. In tisis sectice the primlelve recursive functions (o= joop zrogzomg) are denoted $n_{0}, n_{2}, \ldots$ and the

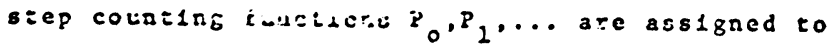
the=. The cosplexity classes $R_{t}^{p}$ are ceflued simllariy to the $e_{t}^{p}$.

Several fnectant ladex cets for clasos of prialtive recieglve functions ar cinflned:

a) nzero - \{functions with zero in range\}

- $\left\{1 \mid 3 \times\left\{p_{1}(x)-0\right]\right\}$

b) $n=-1$ - (even functiono\}

- $i\left\{\mid y \times\left\{p_{1}(x)\right.\right.$ Is even]\}

c) Sizeron rzven

d) SP1nSup - \{functions of fintec support\}

- $\left\{1 \mid \exists k \forall x\left\{x k \Rightarrow p_{1}(x)-0\right\}\right\}$

asc tine location of each of these sets is Indicated 12 plgure 5 . 


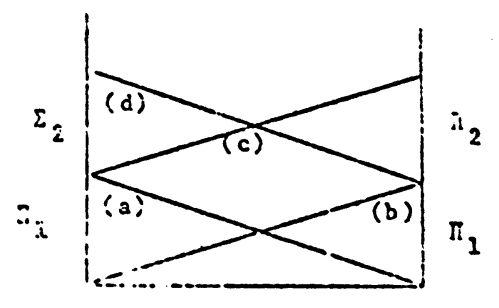

Figures

The orlginal Blum axloms for neasures do not tradiate freaiy to the primltive recursive functlons elare tine: st. e:l cotal functions ind so a sertes of restictions wili be placed on the reasures. Several facte are in order at this polnt.

Facts: a) There are no non-trivinl Index sets which are find 0 or coinite since any inder set contalns a lufinite number ef elements.

$\therefore \Omega \pi_{\tau}^{?}$ is a $\Sigma_{2}$ set, since its rembership problea cr, be expressed: $\exists k \forall x\left[x>k \rightarrow p_{1}(x) \leq \tau(x)\right]$. 
$-48 n-$

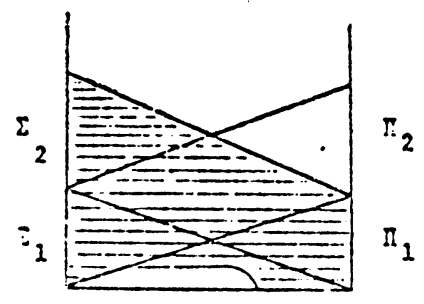

F18ure 6 
Inftlelly the measures constcered are reculred tc be primltive recursive. Thls is reasonable since a function's cost of computation zhe jle be the sase klnd of function as the ore beling sapsted. Inls nermits $\Omega x_{p}^{?}$ to fall in the shaded arca of ploure 6 . Unforturately, thie gesteticr docs rot necessarliy even produse a lirresty, since sl: functions can be assigned to the sami conplexity class. Aiso the classes $R_{t}^{p}$ do not have to be r.e. ead alnost ayy undesirable property can bc found in the classes.

The next restriction to be pleced on measures 1s that each $R_{t}^{P}$ must cortaln at least one func:ion such thet fic: cine \&\& $R_{t}^{P}$ if

$$
n(x)=\left\{\begin{array}{l}
g(x) f(x=, \leq n \\
f(x) f(x=x: n
\end{array}\right.
$$

for sone $n$ then $k E R_{t}^{p}$. Thls provldes the reduction Rzero $\leq_{1} \Omega R_{t}^{P}$ via the function 8 which is defined:

$$
M_{g(1)}(x)=\left\{\begin{array}{l}
g(x) \text { if } 0 \&\left\{y_{1}(c), \ldots, y_{1}(x)\right\} \\
f(x) \text { if } 0 \in\left\{y_{1}(0) \ldots \ldots x_{1}(x)\right\} \\
\text { diverge otherwise }
\end{array}\right.
$$

This forces the ladex sets for complexteg clasees to be in the area cesignated la Figure 7. No hierarchy is 
essured, wal i: does zot bave to bs r.e. as of yet.

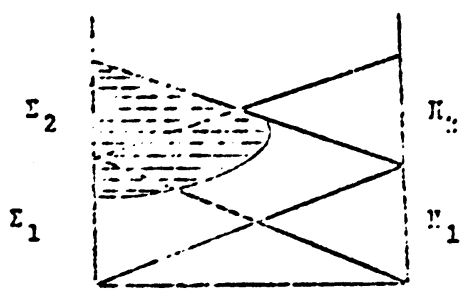

P1gure 7

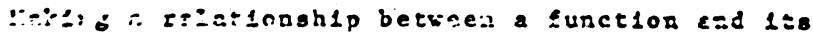
cost aandator; is the next rest:-tet.1nn to be placod on neasureo.

Definitich: sis a epeed 11mit for $\underline{P} 1$ ff for all 1 , $f(x) \geq p_{1}\left(x ; / p_{\&}(x)\right.$ almost everyinere.

Inls speed lin:t can be reasured 10 digles printed por srep if the ac:sure is thought of as steps of computat1on. Zor ime and tape as measures the opeed 
IImle 18 somewhere between $\log (x)$ on 1 depending on how they are defired.

Theorem 3.4: If $P$ has a primltive rccursive speed $11 \mathrm{~m} 1 \mathrm{t}$, then REven $\leq 1 \mathrm{R}_{t}^{\mathrm{P}}$.

Proo:: Assume that $q \in R_{T}^{P}$ and that $s$ is tha speed limle for $P$. Then for aay $p_{1}$ defile:

$$
p_{g(1)}(x)=\left\{\begin{array}{l}
q(x) \text { if } r_{y} \leq x\left[r_{1}(y) \text { is even }\right] \\
t(x) \cdot 8(x)+1 \text { otherwise }
\end{array}\right.
$$

If $P_{1}$ is an even function the $P_{g}(1)=q$ and $g(1) \in \Omega R_{t}^{P}$. But $1 f$ so:: some $2 p_{1}(z)+2$ then:

$$
p_{g(1)}(x)=\left\{\begin{array}{l}
q(x) \text { f०r } x<2 \\
t(x) \cdot B(x)+1 \text { for } x \geq 2
\end{array}\right.
$$

whlch is ojviously a pinftive recursive function (can be computed by a loop program) and due to the definition of opeed $11 \mathrm{mlt \theta}$ :

$$
\forall x \geq z\left\{p_{1}(x) \cdot p_{1}(x) / s(x)>t(x)\right\} \text {. }
$$

This new restricilon allows SRP to range with1n the shaded area lndicited on Flgure 8. At last a hlerarchy 18 assured, because the speed l1ult places a bound on the values of the functions in each complexity 
cless. 3ut, even though this is true the complexity classes st121 do not have to be r.e.

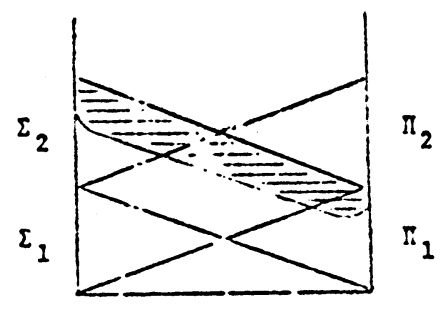

E1gu:e $\varepsilon$

Figure 5 indicates the result of combining the three restrictions mentloned above. Thls follows from the reduction $\Omega$ Evennzeros ${ }_{1} \Omega R_{t}^{P}$. The complexity clases

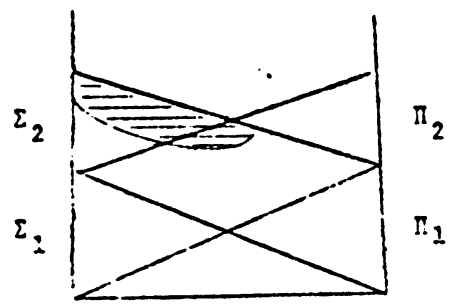

F1gure 9 
are not all r.e. yet, but areurally there 18 a h1erarchy.

Theorem 3.5: If $P$ has a prinltive recurslve speed limit and $R_{t}^{P}$ contalns all finlte varlanto of some function, then RF1nsug $\leq_{1} \Omega R_{t}^{?}$.

Proof: Let $q$ be a function in $P_{t}^{P}$ and se the speed Ilmlt for $P$. Then for any prlilelve recursive $p_{1}$ deflae:

$$
p_{g(1)}(x)=\left\{\begin{array}{l}
q(x) \text { if } ?_{1}(x)=0 \\
g(x) \cdot t(x)+1 \text { otierwlse }
\end{array}\right.
$$

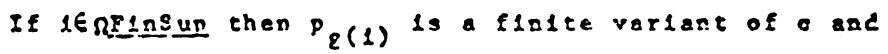
thereforc $g(1) E \Omega R_{t}^{P}$. Otherews e $P_{g}(1)-g^{\cdot} t+1$ 1nf1nLtel often and due to the defingti in of seced 11mits:

$$
F_{g(1)}(x)=?_{g}(1)(x) / s(x)=[s(x) \cdot t(x)+1\} / s(x)>t(x) \text {. }
$$

Thesefore $\&(1) \& \Omega R_{t}^{P}$ if $18 \Omega$ Flnsup

The opeed $11 m i t$ restriction lo recessary to have a hlerarchy. At last conformity has been provided for the primltive recursive functions, as is indleared in Firere 10. 
$-52$.

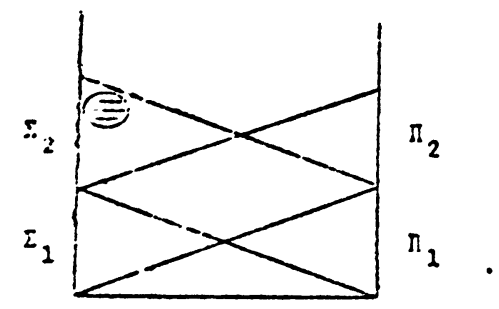

Flgure 10

In fact, the comnlexity classes are r.e. also. 
CHAPIER 4

Conclusion

\subsection{General Remarks}

The major problem with general measures is that the deslrable propertles which sore weasures possess are not found in all measures. Therefore, it is desirable to loolate those measures whlch sre natural and do not have any fathologlcal properties.

One way to do this is to require that the corplexity classes deflned from measures all have liertical properties. Thls was the rationale behind the definstion of conformity, and therefore conformity seems to. be reasonable criterion for measures or any other ax10m system.

From the phenomena exhiblted previously, it would seem that a new axlom 18 needed. If this axion vere that every complextey clage contalna all the flatee variants of at least one function, then conformity usll be achleved. However, this is a restriction on complexity classes and 18 not an axlom in the splelt of the Blum axlomo for measures. Posslbly ooge further rescriction on measures themselves could provide com- 
plexity classes with the finlte variants that are required.

Whenever pasholegleal problems exlst in complexlty hlerarchles, It has been shown that they exist only in the lover levels of the hlerarchy. Ths means that almost all of the conoiexity classes for any measure belong to the same 1-depree, and that the measure conforms "aloogr everywherc". Conditlons that occur in ali sut a finlte nuever of places are accepted in Autorata theory a belro desirable in most cases. In fact, the definition of the complexity classes $R_{t}^{\$}$ contalns an "almost everywhere" clause.

But, In complexlty hlerarchles, the functions which are easiest to corpute, and that are computed most often, occur at the bottom. These very functions are the ones computed in "real ilfe" and therefore are quite fmportant. Facts about thelr complexity ohould be meaningful, and so neasures used should not have any petholcelcal propertles,even for a few clasoes at the bottom of the hlerarshy.

\subsection{The 21 rection of futpre research}

some open broblems and areas for further study are as Lollows. 
a) Conformity on $I_{t}^{0}$ and $I_{t}^{p}$ shoule be studied by placing restralnts on the axloms for pessures.

b) Deflne the class:

Begt - \{flthere 1s "fasteot" program for f\}

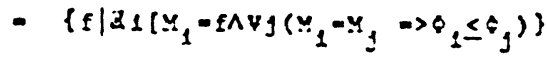

and study rgest with respect to conformity.

c) Speed $11 \mathrm{~m} 1 \mathrm{ts}$, deflned in the last section. should be investlgated with regard to thelr effect on conformlty and other prepertles of measures.

d) Possibly some propertles of classes of recursive functions (along the lines of those in Dekker and kyh111) could be formulated which would have sore slgniflcance when applied to $R_{t}^{\phi}$.

e) The criterion of conformity wight be profitably applied to axiom systems in other areas of Automata thergy. 


\section{BIBLIOGRAPHY}

[2] Blus, $\times$. Machine Independent Theory of the Cozplexi:y of Recurslve Functions, JACM (1967). PP. $322-336$.

[2] Borodir, A. Cosplexiry Classes of Reruralve Fincliong art the rxlstence of comilexity Gads, D.225. of Corguter Sclence Tech. Rpt. 69-41, Corne1T val\%erslty (Aup 1969).

[3] Constable, R., and Hopcroft, J. Dense ac. ion-jense Farilles of Corplexity Classer, jens $1 . n n$. Syr on soliching and Automata Tieory, IREE, (oct. 1969).

(4) Constatie,R. Ex+enting and Refining Rlerarchles of Crifijtable Functions, Computer Sclences Tech. int. i25, Universisy of isconsin (June 1968).

[5] . The operztor Gap, Eenth Ann. Sym. on SuItchlng and Automata Theory, IEE E, Oct. ig69).

[6] Lekker, J.C.E. and Yyi:1Ji. J. Some Theorems on Classes of Recursively inumerable Sets, Trans. AMS, vol. 8Э (1358), PP. 25-59.

(7) Grzegorcyli, A. Some Classes of Fecurglve Functions, 3ozzrzwy Matematyczne, 1953, pp. i-45.

(3) Hartmanis, $J$. and Stearns, R. On the Computational Coxplexity of lignrlthms, Irans. AMS, vol. 117 (1965), pp. 205-306.

[9] Lew1s, F. The Classiflcation of Unsolvable Probleas in Automate Theory, Dept. of Computer

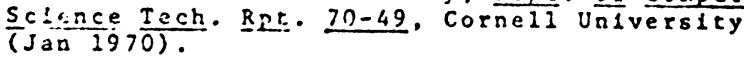

[10] Yccre:qhe, E, and Yeyer. A. Classes of Computable Functions Defi-ed by Bounds on Computation.

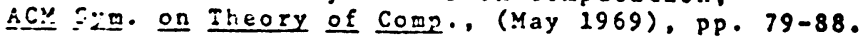

[21] Meyer, A. and P1scher, P. On Compurational speedup,

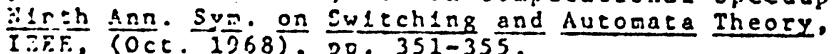


[12] Meyer, A, and Ritchle,; The corolextey of Loop Programs, Proc. 22nd Nee. ACY Conf. $(1967)$. PP. $465-470$.

(13) Myh111, J. IInear Boundec Aucomata, Univ. if Perna. Rpt. No. 6C-22, (Jure 1960).

[14] - Creative Sets, Zelt. fur. math. Losik und Grund der Mach.: vol. i (1955), po. 97-10.

[15] Péter,Roza Recurstive Fuctions, 3d Ed.. Nev Yo5k, 1967.

(26] Rltcble, R. Classes of Fredictably Computahle Functions, Trans. AMS, V. 106 (1963), PF. 139-163.

[17) Robertson, E.L. and Londweter, L.H., On Recurstive Properties of Complexlty Classes, ACY Sym. Theory of Comp.. ( (Tay 1070 ).

[18] Rogers, H.G. Godel llumberlags of Partlal Recurstve Functions, JSL, vol. 23 (1952), pp. 331-3⒈ [19] - computab111ty,, Thecuzsive Functions and Effective

[20] Stearns, R., Hartanis, J. and Lew1s, P., II. Hiferarchles of Memory Linited Computations, lo6s IEEE Conf. Rec. on Swlechlng C1.c. Theory and Los. Design, FF. 179-190.

(21) Young, P. Toward a Theory of Enumerations, Jicy. vol. $16(1969)$, Ff. $328-347$ 